DOI: 10.38136/jgon.731670

\title{
Gebelikte Ağız-Diş Sağıı̆ı ve Periodontal Hastalıkla ilıgili Postpartum Annelerin Bilgi, Farkındalık ve Davranışları
}

\section{The Knowledge, Awareness and Behaviors of Postpartum Mothers Related to Oral and Dental Health and Periodontal Disease in Pregnancy}
M. Ayșe TAYMAN
(1) Orcid ID:0000-0001-8924-6725
Ümit Yasemin SERT 2
(1) Orcid ID:0000-0003-0862-4793

\author{
${ }^{1}$ Ankara Yıldırım Beyazıt Üniversitesi, Diș Hekimliği Fakültesi, Periodontoloji Anabilim Dalı, Ankara, Türkiye \\ ${ }^{2}$ Ankara Șehir Hastanesi, Kadin Doğum Anabilim Dalı, Obstetri ve Jinekoloji Kliniği, Ankara, Türkiye
}

\section{ÖZ}

Amaç: Gebelikte ağız-diş sağlığı ve periodontal hastalıklarla ilgili kadınların bilgi ve davranışlarını değerlendirmektir.

Gereçler ve Yöntem: Bu tanımlayıcı nitelikteki çalışmada, doğum sonrası rastgele seçilmiş annelere, taburcu olmadan önce, çoktan seçmeli 38 sorudan oluşan anket formu dağıtıldı ve doldurmaları istendi.

Bulgular: Annelerin \%2'sinin yaşı 18'in altındaydı, \%11'inin sağlık güvencesi yoktu ve \%27'si asgari ücret altında gelire sahipti. Annelerin \%94'ü sigaranın kendisi ve bebeği için zararlı olduğu konusunda hemfikirdi. Gebeliği boyunca sigara kullanan \%14, günde en az iki kez diş fırçalayan \%38 ve günde en az bir kez yardımcı diş temizlik aracı kullanan \%33 idi. Diş veya diş eti şikayeti olmasına rağmen; diş hekimine başvurmayan $\% 56$, periodontal tedaviyi riskli bulan \%58 ve diş hekimine başvurduğunda diş hekimi tarafından bilgilendirilen sadece \%25'ti. Annelerin \%55'i gebeliğin diş çürüğünü arttırdığına, \%57'si dişlerden kalsiyum kaybedildiğine inanıyordu. \%36'sı gebeliği boyunca diş eti kanaması ve şişliğinin arttığını, \%22'si daha fazla dişinin çürüdüğünü bildirdi. \%58'i fırçalayarak ve diş ipi kullanarak diş eti hastalığını önleyebileceğini biliyordu, ancak \%16'sı diş plağını doğru tanımlayabildi. Periodontal hastalığının olumsuz gebelik sonuçlarına yol açabileceğini düşünen anneler \%10 oranındaydı.

Sonuç: Kadınlar gebelik sırasında periodontal sağlık durumlarında gebelik öncesi döneme göre değişiklikler bildirdiler. Kadınların büyük bir çoğunluğunun periodontal hastalık, gebelik ve doğum sonuçları ile ilgili bilgisi ve farkındalığı yetersizdir. Gebeler ağız hastalıklarının önlenmesi hakkında daha fazla bilgiye ve ağız sağlığı eğitimi programlarına ihtiyaç duymaktadır.

Anahtar kelimeler: Gebelik, Ağız-Diş Sağığı, Periodontal Hastalık

\section{ABSTRACT}

Aim: To evaluate the knowledge and behavior of women about oral-dental health and periodontal diseases in pregnancy.

Materials and Method: In this descriptive study, randomly selected mothers were given a questionnaire consisting of 38 multiple-choice questions before being discharged and asked to complete.

Results: $2 \%$ of mothers were under 18 years old, $11 \%$ had no health insurance and $27 \%$ had income under minimum wage. $94 \%$ of mothers agreed that smoking is harmful for them and their babies. During the pregnancy; $14 \%$ smoking cigarettes, $38 \%$ brushing teeth at least twice a day and 33\% using auxiliary teeth cleaning tool at least once a day. Although they have complaints about teeth or gingivas; $56 \%$ who did not apply to the dentist, $58 \%$ who found periodontal treatment risky and only $25 \%$ informed by the dentist when they applied to the dentist. $55 \%$ of the mothers believed that pregnancy increased tooth decay, $57 \%$ believed that calcium was lost from the teeth. $36 \%$ reported increased gingival bleeding and swelling, $22 \%$ reported that they had more tooth decay during pregnancy. $58 \%$ knew that they could prevent gingival diseases by brushing and using dental floss, but $16 \%$ could correctly identify the dental plaque. Mothers who thought that periodontal disease could lead to negative pregnancy outcomes were $10 \%$.

Conclusion: Women reported changes in periodontal health status during pregnancy compared to the pre-pregnancy period. The knowledge and awareness of the majority of women regarding periodontal disease, pregnancy and birth outcomes are insufficient. Pregnant women need training programs and more information on how to prevent oral diseases.

Key words: Pregnancy, Oral-Dental Health, Periodontal Disease 


\section{Gíriş}

Gingivitis, periodontitis ve diş çürüğü gibi oral hastalıklar, çocuk doğurma çağındaki kadınlarda oldukça yaygın görülen, uzun süre asemptomatik kalabilen, bireylerin ağız sağlığı ve genel sağığını olumsuz etkileyebilen hastalıklardır (1). Annelerdeki karyojenik bakterilerin diş erüpsiyonundan önce bile bebeklere bulaşabileceğine dair kanıtlar vardır ve çocukların diş çürüğü riskinin artmasına neden olur (2). Bu nedenle, iyi bir ağız hijyeni standardını korumak sadece annenin genel refahına katkıda bulunmayacak, aynı zamanda yenidoğanın sağlığını da olumlu etkileyecek ve yaygın oral hastalıkların önlenmesini sağlayacaktır. Gebelerin oral hijyen alışkanlıklarını anlamak, klinisyenlerin hem anne hem de bebek ağız sağlığını iyileştirme planlamalarına yardımcı olacaktır. Gebelikte ve hatta gebelik öncesi planlamada diş bakımı, fırçalama, diş ipi kullanımı, diş taşı temizliği ve kök yüzeyi düzleştirilmesi ve parlatma gibi profesyonel koruyucu ve tedavi edici uygulamalar yoluyla yeterli plak kontrolü sağlanarak sağlıklı ağız ortamına ulaşmak amaçlamaktadır (3).

Gebelik sırasında vücuttaki birçok dokuyu etkileyebilecek hormonal değişiklikler meydana gelir. Diş eti dokusu gebeliğe bağlı değişikliklerden en sık ve şiddetli etkilenen dokudur (4). Gebelerin \%74'ünün orta ila şiddetli gingivitise sahip olduğu ve \%10'unun piyojenik granülom geliştirebileceği gösterilmiştir $(5,6,7)$. Gebeliğin ilk üç ayında diş etinde kanama, şişlik, kızarıklık ve ağrı oluşabilir ve ikinci ve üçüncü üç aylık dönemde daha da artabilir (6). Periodontal hastalığın ana nedeni bakteri plağıdır, ancak gebelikte artan östrojen seviyeleri diş eti dokusunun plaktaki iritan maddelere reaksiyonunun abartılı olmasına sebep olabilir (7). Maternal immüno-duyarlııktaki değişiklikler gingivitis gelişmesine yatkınlıkta artışa neden olduğunu düşündürmektedir. Ayrıca, gebelikte enflamatuar yanıtın güçlü aracıları olan ve immünosupresan görevi gören prostaglandinlerin üretimi yüksek olduğundan diş eti iltihabı artabilir (8). Yapılan bir çalışmada, gingival enflamatuar semptomların gebelik sırasında ağırlaşıı̆ı ve yaşın artması, daha düşük eğitim seviyesi ve işsizlik ile ilişkili olduğu ortaya çıkmıştır (9).

Son yıllarda araştırmacılar periodontal hastalıklar ile olumsuz gebelik sonuçları [erken doğum: <37 hafta ve düşük doğum ağırlığı: <2500 g, (EDDA)] arasındaki ilişkiye odaklanmışlardır (10). Inflamasyon; rahim kasılmalarına, servikal değişikliklere ve erken membran rüptürüne yol açan asıl sebep olmakla birlikte, erken doğumun etiyolojisi çok faktörlüdür. Offenbacher ve ark. (10), gebe kadınlarda tedavi edilmemiş periodontal hastalı- ğın EDDA için önemli bir risk faktörü olabileceğine dair kanıtlar sunmuştur. Bir enfeksiyon kaynağı olan periodontal hastalıktan ortaya çıkan endotoksin (lipopolisakkarit, LPS) gibi bakteri ürünlerinin translokasyonu ve maternal olarak üretilen inflamatuar mediatörlerin etkisi ile EDDA riski artabilir (5). Normal doğum kilolu kontrollerine kıyasla erken doğum yapan annelerde daha yüksek seviyelerde olgun plak ve ilerleyen periodontitis ile ilişkili mikroorganizmalar saptamıştır. Periodontal hastalık ile EDDA arasındaki ilişki rapor eden randomize klinik çalışmalar olmasına rağmen (11), iki koşul arasındaki net ilişki belirsizliğini korumaktadır (12). Bu çelişkili sonuçların sebebi, periodontal hastalığa sahip farkı popülasyonların aynı koşulları ve risk faktörlerini paylaşmayacağı gerçeği olabilir. Her popülasyonda sosyoekonomik, biyolojik ve çevresel belirleyiciler ve çalışmanın deneysel tasarımı gibi birçok değişkenin kontrolü önemlidir. Bununla birlikte, diş eti iltihabının klinik belirteçlerinin gebelikten önce algılanıp algılanmadığı ve kadınların gebelik sırasında periodontal sağlık durumlarında gebelik öncesi ağız sağlığına göre değişiklikler olup olmadığı belirsizliğini korumaktadır.

Düşük sosyo-ekonomik durum, kötü kişisel koruyucu uygulamalar ve diş hekimine başvurma davranışı ile bireylerin ağız sağlığı konusunda yetersiz bilgi düzeyleri ilişkilidir $(13,14)$. Gebeler, gebelik sırasında ağız-diş sağlığındaki olası değişiklikler ve ağız sağlığının önemi hakkında rutin olarak eğitilmeli ve yaygın oral hastalıkları önleyebilecekleri konusunda teşvik edilmelidirler. Gebeler diş hekimi ziyaretlerinin önemi ve gebelik sırasında günlük ağız hijyeni prosedürlerinin iyileştirilmesi ile ilgili genel bilgilere erişebilmelidir. Bununla birlikte, gebe hastalara olası periodontal problemler hakkında bireysel diş hekimliği eğitimi verilip verilmediği ve gebelerin gebelik sırasında ağız-diş sağlığındaki algılanan değişiklikler nedeniyle randevu alıp almadıkları belirsizdir. Bu tanımlayıcı anket çalışmasının amacı, yeni doğum yapmış annelerin gebelik öncesinde ve sırasında; ağız hijyeni, sigara kullanımı, gebeliğin ağız sağlığı üzerine etkileri ve periodontal hastalık konusundaki bilgi, tutum ve davranışlarını değerlendirmektir. Ayrıca kadın doğum uzmanı ve diş hekimlerinin gebelere yönelik tavsiye ve yönlendirmeleri ile gebelerin hekime başvuru davranışları değerlendirilmiştir. Bu çalışma, gebelik sırasında optimal diş, diş eti ve periodontal sağıı̆ın önemi konusunda gebe kadınların bilgi ve motivasyonunu artırabilecek eğitim programlarının tasarlanması için bir temel sağlayacaktır.

\section{GEREÇLER VE YÖNTEM}

Bu kesitsel anket çalışmasında, Ankara Zekai Tahir Burak Kadın Sağlığı Eğitim ve Araştırma Hastanesi ve Ankara Şehir 
Hastanesi'nde yeni doğum yapmış rastgele seçilmiş annelere taburcu olmadan önce anket formu dağıtıldı. Anket içeriği uzman bir periodontolog tarafından (M.A.T.) tasarlandı ve çoktan seçmeli 38 sorudan oluştu. Sorular katılımcıların sosyo-demografik özellikleri; olumsuz gebelik sonuçları, sigara kullanımı, diş fırçası ve yardımcı temizlik araçları kullanımı ile ilgili farkındalık ve davranışları; diş hekimine gitme ve diş hekimine yönlendirilme durumları; ağız-diş sağıı̆ı, periodontal sağlık ve maternal-fetal sağlık arasındaki ilişki hakkındaki farkındalık düzeyi ile ilgili soruları içermektedir. Yeni doğum yapmış annelere çalışmanın amaçları açıklanarak çalışmaya katılmaya gönüllü olan 800 anneye aydınlatılmış yazılı onam formu imzalatılı, isimsoy isim gibi kişisel bilgileri alınmadı ve çoktan seçmeli anket formlarını doldurmaları istendi. Çalışma Temmuz 2019-Nisan 2020 tarihleri arasında gerçekleştirildi. Etik onayı Ankara Zekai Tahir Burak Kadın Sağlığı Eğitim ve Araştırma Hastanesi Etik Kurulundan alındı (karar no:112/2019).

İstatistiksel yöntem

Verilerin tanımlayıcı istatistiklerinde en düşük, en yüksek frekans ve oran değerleri kullanılmıştır. Analizlerde SPSS 26.0 programı kullanılmıştır.

\section{BULGULAR}

Doğum sonrası annelerin demografik verilerine göre 18 yaş altı $16(\% 2)$ ve 35 yaş üstü $108(\% 15)$ olmak üzere toplam 702 anne anket formunu tam olarak doldurarak bu çalışmaya dahil edilmiştir. İlkokul ve daha altı düzeyde 110 (\%16) anne ve üniversite mezunu ise $152(\% 22)$ anne vardır. Annelerin 79'u (\%11) bir sağlık güvencesi olmadığını ve 191'i (\%27) asgari ücret altında gelire sahip olduğunu bildirmiştir (Tablo 1).

Tablo1: Katılımcıların sosyo-demografik özellikleri

\begin{tabular}{|c|c|c|c|}
\hline $\begin{array}{l}\text { Yaşınız } \\
\text { (n:702) }\end{array}$ & $\begin{array}{l}<18 \\
19-25 \\
25-35 \\
>35\end{array}$ & $\begin{array}{l}16 \\
228 \\
350 \\
108\end{array}$ & $\begin{array}{l}2 \\
\% 32 \\
\% 50 \\
\% 15\end{array}$ \\
\hline $\begin{array}{l}\text { Eğitim durumunuz } \\
\text { (n:702) }\end{array}$ & $\begin{array}{l}\text { Illkokul } \\
\text { Ortaokul } \\
\text { Lise } \\
\text { Üniversite }\end{array}$ & $\begin{array}{l}110 \\
189 \\
251 \\
152\end{array}$ & $\begin{array}{l}16 \\
\% 27 \\
\% 36 \\
\% 22\end{array}$ \\
\hline $\begin{array}{l}\text { Sağlık güvenceniz } \\
\text { (n:702) }\end{array}$ & $\begin{array}{l}\text { Var } \\
\text { Yok }\end{array}$ & $\begin{array}{l}623 \\
79\end{array}$ & $\begin{array}{l}\% 89 \\
\% 11\end{array}$ \\
\hline $\begin{array}{l}\text { Aylık geliriniz } \\
(\mathrm{n}: 702)\end{array}$ & $\begin{array}{l}\text { Asgari ücret alt } \\
\text { Asgari ücret üstü } \\
\text { Asgari ücretin } 2 \text { kat } \\
\text { Daha fazla }\end{array}$ & $\begin{array}{l}191 \\
357 \\
88 \\
66\end{array}$ & $\begin{array}{l}\text { \%27 } \\
\% 51 \\
\% 13 \\
\% 9\end{array}$ \\
\hline
\end{tabular}

Çalışmaya katılan annelerin 382'si (\%54) sezeryanla doğum yapmış, bunlardan 261'i (\%37) ilk doğum ve 100'ü (\%14) dört veya daha fazla doğum yapmıştır. Olumsuz gebelik sonuçları olarak (EDDA), 2500 gr'dan az ağırlıklı bebeği olan 217 (\%31) ve 37 haftanın altında bebeği olan ise $300(\% 43)$ anne tespit edilmiştir. Annelerin 64'ü (\%9) gebeliği boyunca düzenli gebelik takibi altında olmadığını bildirmiş̧tir (Tablo 2).

Tablo2: Katıımcıların doğum sonrası demografik özellikleri ve olumsuz gebelik sonuçları

\begin{tabular}{|c|c|c|c|}
\hline $\begin{array}{l}\text { Doğum şekliniz } \\
\text { (n:702) }\end{array}$ & $\begin{array}{l}\text { Normal } \\
\text { Sezeryan }\end{array}$ & $\begin{array}{l}320 \\
382\end{array}$ & $\begin{array}{l}\% 46 \\
\% 54\end{array}$ \\
\hline $\begin{array}{l}\text { Kaçıncı gebeliğiniz? } \\
\text { (n:702) }\end{array}$ & $\begin{array}{l}\text { İlk } \\
\text { İkinci } \\
\text { Üçüncü } \\
\text { Dördüncü ve daha fazla }\end{array}$ & $\begin{array}{l}261 \\
197 \\
144 \\
100\end{array}$ & $\begin{array}{l}\% 37 \\
\% 28 \\
\% 21 \\
\% 14\end{array}$ \\
\hline $\begin{array}{l}\text { Sahip olduğunuz çocuk sayısı } \\
\text { (n:702) }\end{array}$ & $\begin{array}{l}1 \\
2 \\
3 \\
4 \text { ve daha fazla }\end{array}$ & $\begin{array}{l}269 \\
237 \\
136 \\
60\end{array}$ & $\begin{array}{l}\text { \%38 } \\
\% 34 \\
\% 19 \\
\% 9\end{array}$ \\
\hline $\begin{array}{l}\text { Bebeğinizin doğum kilosu } \\
\text { nedir? ( } \mathrm{n}: 702)\end{array}$ & $\begin{array}{l}2500 \text { gr'dan az }^{\prime} \\
2500 \text { gr'dan fazla }^{\prime}\end{array}$ & $\begin{array}{l}217 \\
485\end{array}$ & $\begin{array}{l}\% 31 \\
\% 69\end{array}$ \\
\hline $\begin{array}{l}\text { Bebeğinizin doğum haftası } \\
\text { nedir? (n:702) }\end{array}$ & $\begin{array}{l}37 \text { haftadan az } \\
37 \text { haftadan fazla }\end{array}$ & $\begin{array}{l}300 \\
402\end{array}$ & $\begin{array}{l}\% 43 \\
\% 57\end{array}$ \\
\hline $\begin{array}{l}\text { Gebeliğiniz boyunca düzenli } \\
\text { gebelik takibi altında mıydı- } \\
\text { nız? (n:702) }\end{array}$ & $\begin{array}{l}\text { Evet } \\
\text { Hayır }\end{array}$ & $\begin{array}{l}638 \\
64\end{array}$ & $\begin{array}{l}\% 91 \\
\% 9\end{array}$ \\
\hline
\end{tabular}

Doğum yapan annelerden 116'sı (\%17) gebelik öncesi dönemde sigara kullanmış, 70'i (\%10) gebeliğinin öncesinde ve sonrasında sigara kullanmıştır. Ancak gebeliği boyunca kullandığı sigara miktarını belirten 101 (\%14) anne vardır. Bunlardan $71 ' i$ günde 10 'dan az (\%22), 17'si 10'dan fazla (\%2), 12'si bir paket (\%2) ve 1 tanesi iki paket sigara kullandığını bildirmiştir. Annelerin 659'u (\%94) sigaranın kendisi ve bebeği için zararlı olduğu konusunda hemfikirdir, 11 (\%2) tanesi sigaranın zararlı olmadığını düşünmektedir, $32(\% 5)$ tanesi ise bu konuda bilgisi olmadığını beyan etmiştir (Tablo 3).

Tablo 3: Katılımcıların sigara kullanımı ile ilgili davranış ve farkındalıkları

\begin{tabular}{|c|c|c|c|}
\hline $\begin{array}{l}\text { Sigara kullandınız mı? } \\
\text { (n:702) }\end{array}$ & $\begin{array}{l}\text { Hem gebelik öncesinde hem de } \\
\text { gebelik boyunca kullandım } \\
\text { Gebelik öncesinde kullandım. } \\
\text { Hic kullanmadım }\end{array}$ & $\begin{array}{l}70 \\
116 \\
516\end{array}$ & $\begin{array}{l}\% 10 \\
\% 17 \\
\% 74\end{array}$ \\
\hline $\begin{array}{l}\text { Gebeliğiniz boyunca } \\
\text { sigara kullandıysanız } \\
\text { miktarını belirtiniz. } \\
\text { (n:101) }\end{array}$ & $\begin{array}{l}\text { Günde } 10 \text { 'dan az } \\
\text { Günde } 10^{\prime} \text { dan fazla } \\
\text { Günde } 1 \text { paket } \\
\text { Günde } 2 \text { paket }\end{array}$ & $\begin{array}{l}71 \\
17 \\
12 \\
1\end{array}$ & $\begin{array}{l}\% 22 \\
\% 2 \\
\% 2 \\
\% 0\end{array}$ \\
\hline $\begin{array}{l}\text { Sigara içmenin hamile } \\
\text { kadın ve bebeği üze- } \\
\text { rinde kötü bir etkisi } \\
\text { olduğunu düşünüyor } \\
\text { musunuz? (n:702) }\end{array}$ & $\begin{array}{l}\text { Evet } \\
\text { Hayır } \\
\text { Bilmiyorum }\end{array}$ & $\begin{array}{l}659 \\
11 \\
32\end{array}$ & $\begin{array}{l}\% 94 \\
\% 2 \\
\% 5\end{array}$ \\
\hline
\end{tabular}

Annelerin \%99'unun bireysel bir diş firçası vardır, ancak günde en az iki kez düzenli diş fırçalayan 268 (\%38) anne bulunmaktadır. Fırçalama için en önemli zamanı en yüksek oranla 276 (\%39) kişi yatmadan önce olarak cevaplamıştır. Gebelikte diş fırçalama sıklığının artması gerektiğini düşünen anne sayısı 
471'dir (\%67) (Tablo 4).

Tablo 4: Katılımcıların diş fırçalama ile ilgili bilgi, farkındalık ve davranışları

\begin{tabular}{|c|c|c|c|}
\hline $\begin{array}{l}\text { Size ait bir diş firçanız var } \\
\text { mı? (n:702) }\end{array}$ & $\begin{array}{l}\text { Var } \\
\text { Yok }\end{array}$ & $\begin{array}{l}698 \\
4\end{array}$ & $\begin{array}{l}\% 99 \\
\% 1\end{array}$ \\
\hline $\begin{array}{l}\text { Diş firçalama sıklığınız nedir? } \\
\text { (n:702) }\end{array}$ & $\begin{array}{l}\text { Hiç firçalamıyorum } \\
\text { Ara sıra firçalarım } \\
\text { Günde } 1 \text { kez firçalarım } \\
\text { Günde en az } 2 \text { kez firçalarım }\end{array}$ & $\begin{array}{l}2 \\
116 \\
317 \\
267\end{array}$ & $\begin{array}{l}\% 0 \\
\% 17 \\
\% 45 \\
\% 38\end{array}$ \\
\hline $\begin{array}{l}\text { Gebeliğiniz boyunca diş } \\
\text { firçalama sıklığınız nedir? } \\
(\mathrm{n}: 702)\end{array}$ & $\begin{array}{l}\text { Hiç firçalamadım } \\
\text { Ara sıra firçaladım } \\
\text { Günde } 1 \text { kez firçaladım } \\
\text { Günde en az } 2 \text { kez firçaladım }\end{array}$ & $\begin{array}{l}6 \\
158 \\
270 \\
268\end{array}$ & $\begin{array}{l}\text { \%1 } \\
\% 23 \\
\% 38 \\
\% 38\end{array}$ \\
\hline $\begin{array}{l}\text { Sizce firçalama için en } \\
\text { önemli zaman nedir? } \\
(n: 702)\end{array}$ & $\begin{array}{l}\text { Sabah } \\
\text { Öğlen } \\
\text { Yatmadan önce } \\
\text { Zamanın önemi yok } \\
1 \text { kereden fazla }\end{array}$ & $\begin{array}{l}112 \\
8 \\
276 \\
199 \\
107\end{array}$ & $\begin{array}{l}\text { \%16 } \\
\% 1 \\
\% 39 \\
\% 28 \\
\% 15\end{array}$ \\
\hline $\begin{array}{l}\text { Gebelikte diş firçalama sıklı- } \\
\text { ğının artması gerektiğini dü- } \\
\text { şünüyor musunuz? (n:702) }\end{array}$ & $\begin{array}{l}\text { Evet } \\
\text { Hayır } \\
\text { Fikrim yok }\end{array}$ & $\begin{array}{l}471 \\
68 \\
163\end{array}$ & $\begin{array}{l}\% 67 \\
\% 10 \\
\% 23\end{array}$ \\
\hline
\end{tabular}

Diş fırçası dışında ek temizlik aracı kullanan 468 anne (\%67) vardır. Bunlardan 178'i (\%25) kürdan, 154'ü (\%22) gargara, 123 'ü (\%18) diş ipi olarak en çok kullanılan yardımcı temizlik araçlarını oluşturmaktadır ve 233 (\%33) kişi bu temizlik araçlarından herhangi birini günde 1 kez kullandığını bildirmiştir (Tablo 5).

Tablo5: Katıımcıların yardımcı temizlik araçları kullanımı ile ilgili farkındalık ve davranışları

\begin{tabular}{|c|c|c|c|}
\hline & & $n$ & $\%$ \\
\hline $\begin{array}{l}\text { Diş firçası dışında ek temizle- } \\
\text { me aracı (n:702) }\end{array}$ & $\begin{array}{l}\text { Kullanmıyor } \\
\text { Kullanıyor }\end{array}$ & $\begin{array}{l}234 \\
468\end{array}$ & $\begin{array}{l}\% 33 \\
\% 67\end{array}$ \\
\hline $\begin{array}{l}\text { Diş firçası haricinde dişlerinizi } \\
\text { temizlemek için yardımcı bir } \\
\text { temizlik aracını ya da araçla- } \\
\text { rını kullanıyorsanız işaretleyi- } \\
\text { niz* }(\mathrm{n}: 468)\end{array}$ & $\begin{array}{l}\text { Ara yüz firçası } \\
\text { Diş ipi } \\
\text { Gargara } \\
\text { Kürdan } \\
\text { Misvak }\end{array}$ & $\begin{array}{l}42 \\
123 \\
154 \\
178 \\
46\end{array}$ & \begin{tabular}{l|}
$\% 6$ \\
$\% 18$ \\
$\% 22$ \\
$\% 25$ \\
$\% 7$
\end{tabular} \\
\hline $\begin{array}{l}\text { Yardımcı temizlik aracını } \\
\text { ne sıklıkla kullanıyorsunuz? } \\
\text { (n:468) }\end{array}$ & $\begin{array}{l}\text { Günde bir kez } \\
\text { Haftada birkaç kez } \\
\text { Haftada bir kez } \\
\text { Haftada birden fazla }\end{array}$ & $\begin{array}{l}233 \\
107 \\
87 \\
41\end{array}$ & $\begin{array}{l}\% 33 \\
\% 15 \\
\% 12 \\
\% 6\end{array}$ \\
\hline
\end{tabular}

*birden fazla şık işaretlenmesine müsaade edilmiş sorudur.

Katııımcı annelerin 609'u (\%87) dişi ağrıdığında veya şikayeti olduğunda diş hekimine gitmektedir ve hayatında diş hekimine gitmediğini bildiren 52 (\%7) anne vardır. Gebelik öncesi planlamada diş hekimine giden $323(\% 46)$ anne adayının sadece 131 'ini (\%19) kadın doğum uzmanı diş hekimine yönlendirmiştir. Diş veya diş eti şikayeti olmasına rağmen 552 (\%79) gebenin 390'। (\%56) gibi büyük kısmı diş hekimine gitmeyi doğum sonrasına ertelemiştir. Diş veya diş eti şikayeti nedeniyle diş hekimine giden gebelerin 68'i (\%10) ise diş hekimi tarafından önerilen tedaviyi doğum sonrasına ertelemiştir. Herhangi bir gebeliği boyunca diş hekimine giden 592 (\%84) gebeden yalnızca 173'ü (\%25) "gebelik boyunca ağız sağlığında oluşabilecek olası değişiklikler" hakkında diş hekiminden bilgi aldığını bildirmiştir (Tablo 6).
Tablo 6: Katılımcıların dişhekimine başvurma davranışları ve bilgilendirilme durumları

\begin{tabular}{|c|c|c|c|}
\hline & & $\mathrm{n}$ & $\%$ \\
\hline $\begin{array}{l}\text { Diş hekimine gitme sıklı- } \\
\text { ğınız nedir? (n:702) }\end{array}$ & $\begin{array}{l}\text { Hiç gitmedim. } \\
\text { Dişim ağrıdığında veya şikayetim } \\
\text { olduğunda giderim. } \\
\text { Düzenli giderim. }\end{array}$ & $\begin{array}{l}52 \\
609 \\
41\end{array}$ & $\begin{array}{l}\% 7 \\
\% 87 \\
\% 6\end{array}$ \\
\hline $\begin{array}{l}\text { Gebelik öncesi plan- } \\
\text { lamada diş hekimine } \\
\text { gittiniz mi? ( } \mathrm{n}: 323 \text { ) }\end{array}$ & $\begin{array}{l}\text { Diş hekimine gittim. } \\
\text { Kadın doğum uzmanı tarafindan diş } \\
\text { hekimine yönlendirildim. }\end{array}$ & $\begin{array}{l}192 \\
131\end{array}$ & $\begin{array}{l}\% 27 \\
\% 19\end{array}$ \\
\hline $\begin{array}{l}\text { Gebeliğiniz boyunca diş } \\
\text { hekimine gittiniz mi?* } \\
\text { (n:552) }\end{array}$ & $\begin{array}{l}\text {-Rutin kontrol için gittim. } \\
\text {-Kadın doğum uzmanı tarafindan yönlen- } \\
\text { dirildim. } \\
\text {-Diş veya dişeti şikayetim nedeniyle diş } \\
\text { hekimine gittim. } \\
\text {-Diş veya dişeti şikayetim nedeniyle diş } \\
\text { hekimine gittim ancak önerilen tedaviyi } \\
\text { doğum sonrasına } \\
\text { erteledim. } \\
\text {-Diş veya dişeti şikayetim olmasına rağ- } \\
\text { men diş } \\
\text { hekimine gitmedim, doğum sonrasına } \\
\text { erteledim. }\end{array}$ & $\begin{array}{l}40 \\
43 \\
67 \\
68 \\
390\end{array}$ & $\begin{array}{l}\% 6 \\
\% 6 \\
\% 10 \\
\% 10 \\
\text { \%56 }\end{array}$ \\
\hline $\begin{array}{l}\text { Diş hekimine gittiyseniz } \\
\text { eğer, gebelik boyunca } \\
\text { ağız sağlığınızdaki olası } \\
\text { değişiklikler hakkında } \\
\text { bilgi aldınız mı? (n:592) }\end{array}$ & $\begin{array}{l}\text { Evet } \\
\text { Hayır }\end{array}$ & $\begin{array}{l}173 \\
419\end{array}$ & $\begin{array}{l}\% 25 \\
\% 60\end{array}$ \\
\hline
\end{tabular}

*birden fazla şık işaretlenmesine müsaade edilmiş sorudur

Yeni doğum yapmış 659 annenin 386'sı (\%55) gebeliğin diş çürüğü oranını arttırdığını, 657 annenin 286'sı (\%41) gebeliğin diş eti kanamasını artırdığını ve 279'u (\%40) bu kanamanın bir enfeksiyon belirtisi olduğunu düşünmektedir. 613 annenin 408'i (\%58) gebelik boyunca hormonlar nedeniyle diş etinin büyüyebileceğini, 575 annenin 400'ü (\%57) gebelikte dişlerden kalsiyum kaybedildiğini, 119'u (\%17) ise gebeliğin diş kaybına neden olduğunu düşünmektedir. 618 annenin 155’i (\%22) gebeliği boyunca daha fazla dişi çürüdüğünü, 254'ü (\%36) diş etinde kanama ve şişliğin arttığını ve 243'ü (\%35) ağız-diş sağlığının gebelikten olumsuz etkilendiğini bildirmiştir. 615 anneden 409'u (\%58) gebelikte diş taşı temizliği ve diş eti tedavisinin riskli olduğunu ve doğum sonrasına ertelenmesi gereken bir tedavi olduğunu düşünmektedir (Tablo 7).

Tablo 7: Katılımcıların ağız-diş sağlığı, periodontal sağlık ve maternal-fetal sağlık arasındaki ilişki hakkında bilgi-görüş ve farkındalık düzeyi

\begin{tabular}{|c|c|c|c|}
\hline & & $\mathrm{n}$ & $\%$ \\
\hline $\begin{array}{l}\text { Doğru olduğunu düşün- } \\
\text { düğünüz cümleyi işaretle- } \\
\text { yiniz. (n:659) }\end{array}$ & $\begin{array}{l}\text { Gebelik diş çürüğg̈nün arttrıyor. } \\
\text { Gebelik ile diş çürüğü arasında ilişki yoktur. } \\
\text { Cevapsız }\end{array}$ & $\begin{array}{l}386 \\
273 \\
43\end{array}$ & $\begin{array}{l}\% 55 \\
\% 39 \\
\% 6\end{array}$ \\
\hline $\begin{array}{l}\text { Doğru olduğunu düşün- } \\
\text { düğünüz cümle ya da } \\
\text { cümleleri işaretleyiniz.* } \\
\text { (n:657) }\end{array}$ & $\begin{array}{l}\text { Gebelik daha fazla dişeti kanamasına neden oluyor. } \\
\text { Gebelik daha fazla dişeti kanamasına neden olmaz. } \\
\text { Dişeti kanaması bir enfeksiyon göstergesidir, normal değildir. } \\
\text { Cevapsız }\end{array}$ & $\begin{array}{l}286 \\
120 \\
279 \\
47\end{array}$ & $\begin{array}{l}\% 41 \\
\% 17 \\
\% 40 \\
\% 7\end{array}$ \\
\hline $\begin{array}{l}\text { Doğru olduğunu düşün- } \\
\text { düğünüz cümleyi işaretle- } \\
\text { yiniz. (n:613) }\end{array}$ & $\begin{array}{l}\text { Gebelik boyunca hormonlardan dolayı dişetleri büyüyebilir. } \\
\text { Gebelikte hormonal değişikliklerin dişetleri üzerinde etkisi } \\
\text { yoktur. } \\
\text { Cevapsız }\end{array}$ & $\begin{array}{l}408 \\
205 \\
89\end{array}$ & $\begin{array}{l}\% 58 \\
\% 29 \\
\% 13\end{array}$ \\
\hline $\begin{array}{l}\text { Doğru olduğunu düşün- } \\
\text { düğünüz cümle ya da } \\
\text { cümleleri işaretleyiniz.* } \\
\text { (n:575) }\end{array}$ & $\begin{array}{l}\text { Gebelik dişlerden kalsiyum kaybedilmesine neden oluyor } \\
\text { Gebelik diş kaybına neden oluyor. } \\
\text { Gebelik diş kaybına, dişlerden kalsiyum kaybına neden olmaz. } \\
\text { Cevapsız }\end{array}$ & $\begin{array}{l}400 \\
119 \\
123 \\
60\end{array}$ & $\begin{array}{l}\% 57 \\
\% 17 \\
\% 18 \\
\% 9\end{array}$ \\
\hline $\begin{array}{l}\text { Doğru olduğunu dü- } \\
\text { şündüğünüz cümle ya } \\
\text { da cümleleri işaretleyi- } \\
\text { niz.*(n:618) }\end{array}$ & $\begin{array}{l}\text { Gebeliğim boyunca daha fazla dişim çürüdü. } \\
\text { Gebeliğim boyunca dişetimde kanama ve şişlik artt. } \\
\text { Gebeliğin ağı-diş sağlığıma olumsuz etkisi vardır. } \\
\text { Cevapsız }\end{array}$ & $\begin{array}{l}155 \\
254 \\
243 \\
66\end{array}$ & $\begin{array}{l}\% 22 \\
\% 36 \\
\% 35 \\
\% 9\end{array}$ \\
\hline $\begin{array}{l}\text { Doğru olduğunu düşün- } \\
\text { düğünüz cümleyi işaretle- } \\
\text { yiniz. (n:615) }\end{array}$ & $\begin{array}{l}\text { Gebelikte diştaşı temizliği ve dişeti hastalığının tedavisi ya- } \\
\text { pılabilir. } \\
\text { Gebelikte diştaşı temizliği ve dişeti tedavisi risklidir, doğum } \\
\text { sonrasına ertelenmelidir. } \\
\text { Cevapsız }\end{array}$ & $\begin{array}{l}206 \\
409 \\
87\end{array}$ & $\begin{array}{l}\% 29 \\
\% 58 \\
\% 12\end{array}$ \\
\hline
\end{tabular}

*birden fazla şık işaretlenmesine müsaade edilmiş sorudur. 
Çalışmaya katılan yeni doğum yapmış annelerin sadece 109'u (\%16) "plak nedir?" sorusuna "diş üzerindeki yumuşak eklentilerdir" diyerek doğru cevap vermiştir, 309'unun (\%44) plak hakkında bir fikri yoktur. Plağın diş eti hastalığına sebep olabileceğini söyleyerek doğru cevap veren 145 (\%21) anne vardır ve 308'i (\%44) yine plağın neden olabileceği durumu bilmemektedir. Diş eti hastalığını fırçalayarak ve diş ipi kullanarak önleyebileceğini bilen anne sayısı 410'dur (\%58) ve 207'si (\%29) diş eti hastalığını nası önleyeceğini bilmediğini bildirmiştir. 280 (\%40) anne gebelikte iltihaplı diş eti hastalığına neden olan faktörün diş plağı olduğunu, 219 (\%31) anne hormonlar olduğunu, 191(\%27) anne inmal edilen diş firçalama olduğunu söylemiştir. Gebelikte var olan diş eti hastalığının erken doğuma sebep olabileceğini düşünen 77 (\%11) anne ve düşük doğum ağırlıklı bebek doğmasına sebep olabileceğini düşünen ise 64 (\%9) anne vardır. Annelerin olumsuz gebelik sonuçları ile ilgili büyük bir oranı (sırasıyla \%47 ve \%55) bilgi sahibi olmadığını bildirmiştir (Tablo 8).

Tablo8: Katılımcıların periodontal hastalık ve olumsuz gebelik sonuçlarına etkisi ile ilgili farkındalık düzeyi

\begin{tabular}{|c|c|c|c|}
\hline & & $\mathrm{n}$ & $\%$ \\
\hline \multirow{4}{*}{$\begin{array}{l}\text { Plak nedir? } \\
(\mathrm{n}: 702)\end{array}$} & Diş üzerindeki yumuşak birikintilerdir. & 109 & $\% 16$ \\
\hline & Diş üzerindeki sert birikintilerdir. & 215 & $\% 31$ \\
\hline & Diş üzerindeki boyanmalardır. & 69 & $\% 10$ \\
\hline & Bilmiyorum & 309 & $\% 44$ \\
\hline \multirow{4}{*}{ Plak neye neden olabilir? (702) } & Renk değişikliğine & 139 & $\% 20$ \\
\hline & Dişte form bozukluğu ve deformitelere & 110 & $\% 16$ \\
\hline & Dişeti hastalığına & 145 & $\% 21$ \\
\hline & Bilmiyorum & 308 & $\% 44$ \\
\hline \multirow{4}{*}{ Dişeti kanaması neyi gösterir? (n:702) } & Iltihaplı dişetini & 348 & $\% 50$ \\
\hline & Sağlıklı dişetini & 16 & $\% 2$ \\
\hline & Dişeti çekilmesini & 174 & $\% 25$ \\
\hline & Bilmiyorum & 164 & $\% 23$ \\
\hline \multirow{4}{*}{$\begin{array}{l}\text { Diş eti hastalığını nasıl önleyebilirsi- } \\
\text { niz?* }(n: 702)\end{array}$} & Yumuşak diyet kullanarak & 31 & $\% 4$ \\
\hline & Fırçalayarak ve diş ipi kullanarak & 410 & $\% 58$ \\
\hline & Vitamin kullanarak & 82 & $\% 12$ \\
\hline & Bilmiyorum & 207 & $\% 29$ \\
\hline \multirow{4}{*}{$\begin{array}{l}\text { Gebe kadınlarda iltihaplı diş eti hastalı- } \\
\text { ğına sebep olan şey nedir?* (n:702) }\end{array}$} & Diş plağı & 280 & $\% 40$ \\
\hline & Hormonal değişiklikler & 219 & $\% 31$ \\
\hline & İhmal edilen diş firçalama & 191 & $\% 27$ \\
\hline & Bilmiyorum & 142 & $\% 20$ \\
\hline \multirow{3}{*}{$\begin{array}{l}\text { Gebelikte var olan dişeti hastallı̆ııın } \\
\text { erken doğuma sebep olduğunu düşü- } \\
\text { nüyor musunuz? (n:702) }\end{array}$} & Evet & 77 & $\% 11$ \\
\hline & Hayır & 297 & $\% 42$ \\
\hline & Bilmiyorum & 328 & $\% 47$ \\
\hline \multirow{3}{*}{$\begin{array}{l}\text { Gebelikte var olan dişeti hastalığının, } \\
\text { bebeğin düşük doğum ağırlığı ile doğ- } \\
\text { masına sebep olabileceğini düşünüyor } \\
\text { musunuz? }(\mathrm{n}: 702)\end{array}$} & Evet & 64 & $\% 9$ \\
\hline & Hayır & 252 & $\% 36$ \\
\hline & Bilmiyorum & 386 & $\% 55$ \\
\hline
\end{tabular}

\section{TARTIŞMA}

Çoğu insan tarafından ileri aşamalara ulaştığında farkedilen periodontal hastalığın erken aşamalarda kontrolü ve idamesi için bu hastalıkların bilinmesi önemlidir. Özellikle periodontal hastalıkların abartılı seyrettiği gebelik dönemi özel bir öneme sahiptir ve bu dönemde mevcut olan enflamatuar periodontal hastalık EDDA'ya yol açabilir $(10,11,15,16)$. Toygar ve ark. 3.576 yeni doğum yapan annenin periodontal durumlarını incelemiş ve EDDA ile periodontal durumun ilişkili olduğunu ortaya koymuşlardır (16). Ceylantekin ve ark. da (17) erken doğum yapanlarda daha kötü ağız hjyeni ve daha fazla çürük tespit etmişlerdir. Periodontal hastalıkların önlenmesi ve tedavisine ilişkin önleyici ve eğitimsel faaliyetlerle bu olumsuz sonuçların önüne geçilebilir. Ne yazık ki, genel popülasyonda periodontal hastalıkların bilgi ve farkındalığına ilişkin veriler azdır.

Dental plak gingivitisin başlaması ve ilerlemesinde önde gelen etyolojik faktör olmasına rağmen, gebelik gingivitisi gebelik sırasındaki immünolojik-hormonal değişiklikler ve patojenlerin bileşimindeki değişikliklerle de ilişkilendirilir $(18,19)$. Bu nedenle, ağız hijyeni talimatlarına uymak önleyici stratejilerin bir parçası olmalıdır (20). Ürdün'de yapılan bir çalışmada (21) 'plağı tanımlamak' konusunda gebe kadınların \%16'sı, 'plağın neye neden olabileceği' konusunda ise \%23'ü doğru cevap vermiştir. Bizim çalışmamızda ise bu çalışmayla benzer şekilde doğru cevap veren kadınlar sırasıyla \%16 ve \%21'dir. Bu sonuçlar, gebe kadınların periodontal hastalıkların primer etiyolojik faktörü hakkında bilgilerinin zayıf olduğunu göstermektedir. Ancak sonuçlarımıza göre gebe annelerin \%58'i fırçalayarak ve diş ipi kullanarak diş eti hastalığını önleyebileceğini bilmektedir ve \%67'si fırçalamanın gebelikte artması gerektiğine inanmaktadır, yine Ürdünlü annelerde bu oran $\% 55$ 'dir. Ancak çalışmamızda günde 2 defa düzenli diş fırçaladığını bildiren anne oranı \%38'dir, Kaydırak ve ark. (22) bu oranı \%30 vermiştir, Çin'de yapılan çalışmada ise \%32'dir (23). Ceylantekin ve ark.'nın çalışmasında (17) ise doğum yapan annelerin \%78'inin düzenli fırçalama alışkanlığı yoktur veya dişlerini arada fırçaladıklarını bildirmişlerdir. Bu bilgiler ışığında, ağız hijyeni sağlanmasının gerekliliği konusunda var olan yüksek farkındalık düzeyinin, katılımcıların doğru bilgi ve davranış düzeyine yansımadığını göstermektedir.

Çalışmamızda diş fırçası haricinde temizlik araçlarından herhangi birini günde 1 kez kullandığını bildiren anne $\% 33$ civarındadır ve örneğin diş ipi kullanımı \%18'de kalmaktadır. Bu durum Hollandalı annelerin \%70'inin günde en az iki kez dişlerini fırçaladığını ve \%62'sinin bir veya daha fazla diş arası temizleme cihazı kullandığını bildiren önceki çalışmaya (24) göre düşük bir orandır. 1991 yılında Hollanda nüfusunun yaklaşık \%95'inin günde ortalama iki kez dişlerini fırçaladığını ve diğer temizlik cihazlarının kullanımının çok yaygın olduğunu görülmektedir (25). Diğer ülkelerden yapılan çalışmalar, gebe kadınlar arasındaki ağız hijyeni alışkanlıklarının ülkeye göre değişebileceğini $(26,27)$ ve gebelik sırasında ağız hijyeni uygulamalarıyla ilgili ırksal, etnik ve ekonomik eşitsizliklerin mevcut olduğunu göstermiştir (28).

Çalışmamızda annelerin \%14'ü gebeliği boyunca sigara kullandığını bildirmişstir. 2010 yılında Avrupa Birliği, Euro-Perıstat verilerine göre gebelik sırasında sigara içme oranının \%5 ile 
\%19 arasında değiştiğini bildirmektedir (29). Hollandalı kadınların \%9'u gebelik sırasında sigara içmektedir (24). Finlandiya'da yapılan bir araşııma, erken sigarayı bırakmanın olumsuz perinatal sonuç risklerini azalttığını göstermiş ve gebelik planlayan genç kadınlara, gebelik sırasında sigara içmenin sonuçları hakkında eğitim verilmesi gerektiği sonucuna varmıştır (30). Çalışmamızda \%94 gibi büyük bir oranda anneler sigaranın kendisi ve bebeği için zararlı olduğu bilmektedir ancak gebelikte var olan diş eti hastalığının olumsuz gebelik sonuçlarına sebep olabileceğini düşünen ortalama anne oranı sadece $\% 10$ 'dur. Anne eğitimi programlarında sağlığın çeşitli yönleri ile ilgilenilirken, periodontal sağlık genellikle göz ardı edilmektedir. Ülkemizde ve diğer ülkelerde yapılan çalışmalar bu eğitim desteğinin düşük gelirli ve düşük eğitim seviyesine sahip kadınlar için önemini vurgulamaktadır $(17,21,31)$. İzmir'de gebelerin ağız diş sağlığını geliştirmek üzerine yapılan kapsamlı bir çalışmada, annelerin gebelikteki diş eti hastalıkları hakkındaki farkındalık düzeyi artmış, erken dönem diş çürüklerinin nedenleri ve koruyucu davranışlar hakkındaki bilgileri gelişmiştir (31).

Diş kliniklerine başvurmanın önündeki engellerle ilgili olarak gebe olmayan kadınlarda \%34 oranda 'tedaviyi gerekli görmemek', \%22 oranında 'diş bakımı maliyeti' gerekçe gösterilirken; gebe kadınlarda \%61 oranında 'diş hekimi korkusu' gerekçe gösterilmiştir (5). Bunun nedeni, gebe kadınların diş tedavisinin kendisini ve bebeğini nasıl etkileyebileceği konusunda bilgi eksikliğinden kaynaklanıyor olabilir. Başka bir çalışmada gebe kadınların sadece \%11'i ağız sağlığındaki algılanan değişiklikler nedeniyle diş kliniğine başvurdu (24). Bizim çalışmamızda ise; annelerin \%87 gibi büyük bir oranı rutin hayatında dişi ağrıdığında ya da şikayeti olduğunda diş hekimine gitmekte ve gebeliği boyunca şikayeti üzerine diş hekimine gittiğini belirtenlerin oranı $\% 20$ 'ye düşmekte, $\% 56$ 'sı diş hekimine gitmeyi doğum sonrasına ertelemekte ve $\% 58$ 'i gebelikte periodontal tedaviyi riskli bulmaktadır. Diğer çalışmalar, kadınların gebelik sırasında diş hekimine yapılan ziyaretlerle ilgili davranışlarının şikayetlerin niteliğine bağı olabileceğini göstermiştir. Diş ağrısına sahip olmak, diş eti iltihabının bir veya daha fazla belirtisine sahip olmaktan daha fazla diş hekimine danışılmasına neden olur $(26,27,32)$. Diş hekimleri ve kadın-doğum uzmanları gebelik sırasında kadınlara ağız sağı̆ğındaki değişiklikler konusunda bilgi sağlamada önemli rol oynayabilir. Periodontal depridman sıkığının artıııması, etkili fırçalama ve interdental temizleme, florür ve antimikrobiyal ağız çalkalama solusyonlarının evde kullanımı dahil oral önleyici programların önerilmesi doğum öncesi başlatııp, gebelik boyunca gerçekleştirilirse, gebe kadın ve çocuğu üzerinde olası periodontal hastalık riski azaltılabilir (33). Hayal kırıklığı yaratan bulgumuz ise; gebelik sırasında diş hekimlerine giden gebelerden yalnızca \%25'i diş hekimi tarafından ağız sağlığı korunmasına ilişkin spesifik bilgi ve tavsiyeler almıştır. Bu oran Hollanda'da \%50'dir (24). Ülkemizde yapılan bir çalışmada ise gebelerin \%80'i gebeliklerinde diş hekimine gitmemiş ve \%88'i ağız-diş bakımı konusunda doktor veya hemşireden herhangi bir bilgi almamıştır (17), diğer bir çalışmada gebeliğinde ağız-diş sağlığı konusunda bilgi aldığını belirten anneler \%28'dir (22). Önleyici-koruyucu bakış açısından, periodontal hasta eğitiminin bu yönü daha fazla ilgiyi hak etmektedir. Gebelik ve diş eti durumu ile ilgili çalışmaların çoğunda gebe kadınların, doğum sonrası kadınlara kıyasla daha fazla diş eti kanaması rapor ettiğini bildirdiler. Bu fark, gebe kadınlar gebe olmayan kadınlarla karşılaştırıldığında daha da büyüktür. Hollandalı kadınlar gebelik sırasında gebelik öncesi döneme göre daha fazla kanamalı, kırmızı, ağrıı ve şişmiş diş etleri algısı olduğunu bildirmişlerdir ve algılanan farkılıklar klinik olarak da belirgindir (24). Doğum sonrası Avustralyalı kadınlardan oluşan bir grubun \%60'inde (34), Ingiltere'de ise \%44'ünde (35) diş eti kanaması vardı ancak klinik semptomları belirlemek için kendi kendini raporlama yöntemini kullanmanın sınırlaması olabilir. Bizim çalışmamızda annelerin \%36'sı gebeliğinde daha fazla diş eti kanaması ve şişlik olduğunu rapor etmiştir. Önceki çalışmalar periodontal hastalık için kendini bildirme ve klinik değerlendirme sonuçlarının popülasyonlara ve bildirdiği sonuçlara göre değişebileceğini göstermiştir (36). Periodontal hastalık durumunu tahmin etmek için kendini raporlama yöntemini kullanmanın fizibilitesini belirlemeye çalışan Taylor ve Borgnakke (37), kendi kendini raporlamanın periodontal hastalığın sürveyansı (izleme, gözetleme) için geçerli olabileceği sonucuna varmıştır. Airila-m ansson et al. (38) ve Eke et al. (39) kendi kendini bildiren periodontal problemlerin klinik değerlendirmelerle doğrulandığını göstermiştir. Bizim çalışmamızda da gebelik döneminde gingivitis belirtilerinin algılanması daha fazlaydı, bu durum anlamlı fark gösteren önceki çalışmaları desteklemektedir (24). Gebelikteki gingivitis şiddetinin ve doğum sonrası post-periodontal iyileşmenin, gebelik öncesi dönemde var olan periodontal patolojiye bağı olup olmadığı ise belirsizliğini korumaktadır.

Gebelik nedeniyle diş tedavilerini ertelemek hatalıdır ve belirli kurallara uyarak özellikle gebeliğin 2. üç aylık döneminde her türlü tedavi yapılabilmektedir (40). Ancak çalışmamızda annelerin \%58'i gebelikte tedaviyi riskli bulmakta ve ertelemektedir. Gebe kadınların diş hekimlerine yönlendirilmesi, algılanan inti- 
yaç ile hizmetlerin alınması arasındaki engellerin azaltımasına yardımcı olabilir. Sonuçlarımıza göre gebelikte dişlerden kalsiyum kaybedildiği (\%57) ve gebeliğin diş çürüğünü arttırdığı (\%55) yanlış inanışlarına sahip gebe sayısı azımsanmayacak çoğunluktadır. Bu oranları Kaydırak ve ark. $\% 69$ ve $\% 58$ olarak bulmuştur (22). Diş hekimleri doğru ve yeterli bilgiyi sağlayarak, gebelik sırasında ağız hijyeni uygulamalarını yoğunlaştırmanın faydalarını göstererek, gingivitis ve diş çürüğünün azaltılmasına yardımcı olmalıdır.

\section{SONUÇ}

Kadınlar gebelik sırasında periodontal sağlık durumlarında gebelikten önceki döneme göre değişiklikler bildirmişlerdir. Kadınların büyük bir çoğunluğunun periodontal hastalık, gebelik ve doğum sonuçları ile ilgili bilgisi ve farkındalığı yetersizdir. Gebeler ağız hastalıklarııın önlenmesi hakkında daha fazla bilgi ve ağız sağlığı eğitimi programlarına intiyaç duymaktadır. Ağız hijyeni uygulama talimatlarının yoğunlaşııılması, gebelik sırasında diş eti iltihabı semptomlarının azaltılmasında önemli rol oynayabilir. Gebelik takip ve doğum bakım merkezlerinde uygulanacak ağız sağlığı eğitimi programlarının gebe kadınların davranışları üzerindeki uzun dönemli etkilerini değerlendirmek için ileri çalışmalara intiyaç vardır. Periodontal hastalık ile EDDA arasında güçlü bir korelasyon olup olmadığını ve periodontal tedavinin EDDA riskini azaltıp azaltamayacağını belirlemek için daha fazla çalışmaya intiyaç vardır.

\section{REFERANSLAR}

1. Petersen PE (2003) The World Oral Health Report 2003: continuous improvement of oral health in the 21st century-the approach of the WHO Global Oral Health Programme. Commun Dent Oral Epidemiol 31(Suppl 1):3-23

2. Berkowitz RJ. Mutans streptococci: acquisition and transmission. Pediatr Dent 2006; 28:106-9.

3. Azofeifa A, Yeung LF, Alverson CJ, Beltrán-Aguilar E. Oral Health Conditions and Dental Visits Among Pregnant and Nonpregnant Women of Childbearing Age in the United States, National Health and Nutrition Examination Survey, 1999-2004. Prev Chronic Dis. 2014;11:E163.

4. Leine MA. Effect of pregnancy and dental health. Actaodontol Scand 2002; 60:257-64.

5. Taani DQ. Periodontal awareness and knowledge, and pattern of dental attendance among adults in Jordan. Int Dent J 2002; 52: 94-8.

6. G€ursoy M, Pajukanta R, Sorsa T, K€on€onen E. Cli- nical changes in periodontium during pregnancy and post-partum. J Clin Periodontol 2008; 35: 576-83.

7. Massoni RSS, Aranha AMF, Matos FZ, Guedes OA, Borges ÁH, Miotto $M$ et al. Correlation of periodontal and microbiological evaluations, with serum levels of estradiol and progesterone, during different trimesters of gestation. Sci Rep. 2019; 13;9:11762.

8. Wu M, Chen SW, Jiang SY. Relationship between gingival inflammation and pregnancy. Mediators Inflamm. 2015;2015:623427.

9. Taani DQ, Habashna R, Hammad MM, Butieha A. The periodontal status of pregnant women and its relationship with socio-demographic and clinical variables. J Oral Rehab 2003; 30: $440-5$.

10. Offenbacher S, Kats V, Fertik G. Periodontal disease as a possible risk factor for preterm low birth weight. J Periodontal 1996; 67:1103-13.

11. Lopez NJ, Smith PC, Gutierrez J. Periodontal therapy may reduce the risk of preterm low birth weight in women with periodontal disease: a randomized controlled trial. J Periodontol. 2002; 73:911-24.

12. Michalowicz BS, Hodges JS, DiAngelis AJ, Lupo VR, Novak MJ, Ferguson JE et al. Treatment of periodontal disease and the risk of preterm birth. N Engl J Med. 2006; 2;355:188594

13. Thomas NJ, Middleton PF, Crowther CA. Oral and dental health care practices in pregnant women in Australia: a postnatal survey. BMC Pregnancy and Childbirth. 2008; 8:13.

14. Adeniyi A, Agbaje O, Braimoh M, Ogunbanjo OS, Olubumi M, Olubunmi OA, et al. Survey of the Oral Health, Knowledge and Practices of Pregnant Women in a Nigerian Teaching Hospital. African Journal of Reproductive Health. 2011; 15:149.

15. Offenbacher S, Lieff S, Bogges KA, Murtha AP, Madianos PN, Champagne $\mathrm{CM}$ et al. Maternal periodontitis and prematurity: part 1 - obstetric outcome of prematurity and growth restriction. Ann Periodontol 2002; 7: 90-94.

16. Toygar H, Seydaoglu G, Kurklu S, Guzeldemir E, Arpak N. Periodontal health and adverse pregnancy outcome in 3,576 Turkish women. J Periodontol 2007; 78:2081-94.

17. Ceylantekin Y, Alikaya C, Köken GN. Ağız ve Diş Hijyeninin Erken Doğumla İlişkisinin Değerlendirimesi. Turkiye Klinikleri J Gynecol Obst 2011; 21:184-9. 
18. Carillo-de-Albbornoz A, Figuero E, Herrera D, Cuesta $P$, Bascones- Martinez A. Gingival changes during pregnancy: III. Impact of clinical, microbiological, immunological and socio-demographic factors on gingival inflammation. J Clin Periodontol 2012; 39:272-83.

19. Figuero E, Carillo-de-Albornoz A, Herrera D, Bascones-Mart_ınez A. Gingival changes during pregnancy: I. Influence of hormonal variations on clinical and immunological parameters. J Clin Periodontol 2010; 37:220-9.

20. Geisinger ML, Geurs NC, Bain JL, Kaur M, Vassilopoulos PJ, Cliver SP et al. Oral health education and therapy reduces gingivitis during pregnancy. J Clin Periodontol 2014; 41:141-8.

21. Alwaeli HA, Al-Jundi SH. Periodontal disease awareness among pregnant women and its relationship with soci0-demographic variables. Int J Dent Hyg. 2005; 3:74-82.

22. Kaydırak, MM; Şahin, NH; Can, MM; Koray, M. Gebelerin Ağız ve Diş Sağlığına Illişkin Bilgi ve Görüşleri. SDÜ Saglik Bilimleri Dergisi. 2018; 9:11-6.

23. Zhu L, Petersen PE, Wang H, Bian J, Zhang B. Oral health knowledge, attitudes and behaviour of adults in China. International Dental Journal. 2005; 55:231-41.

24. Stelmakh V, Slot DE, van der Weijden GA. Self-reported periodontal conditions among Dutch women during pregnancy. Int J Dent Hyg. 2017;15:e9-e15.

25. Visser RS, Heling GW, Burgersdijk RC, van't Hof MA, Kalsbeek H, Truin GJ. Dental self care of the dentate Dutch population: oral hygiene. Ned Tijdschr Tandheelkd 1991;97: 227-9.

26. Christensen LB, Jeppe-Jensen D, Petersen PE. Self-reported gingival conditions and self-care in the oral health of Danish women during pregnancy. J Clin Periodontol 2003; 30:949-53.

27. Hashim R. Self-reported oral health, oral hygiene habits and dental service utilization among pregnant women in United Arab Emirates. Int J Dent Hyg 2012; 10:142-6.

28. Claas BM, Ellison-Loschmann L, Jeffreys M. Self-reported oral health care and access to oral health information among pregnant women in Wellington, New Zealand. N Z Med J 2011; 124:37-50.

29. european-perinatal-health-report-2010. Erişim Tarihi: 2.05.2020. Available from: http://www.europeristat.com/reports/.html.
30. R€ais€anen S, Sankilampi U, Gissler M, Kramer MR, Hakulinen-Viitanen T, Saari J et al. Smoking cessation in the first trimester reduces most obstetric risks, but not the risks of major congenital anomalies and admission to neonatal care: a population- based cohort study of 1,164,953 singleton pregnancies in Finland. J Epidemiol Community Health 2014; 68:15964

31. Öcek ZA, Eden E, Türk M, Çakır N. Mid-term assessment of a programme conducted in Izmir for improving oral health in pregnant women and reducing caries in children: changes in the level of knowledge of the mothers.Türkiye Halk Sağlığı Dergisi 2016; 14:68-80.

32. Honkala S, Al-Ansari J. Self-reported oral health, oral hygiene habits, and dental attendance of pregnant women in Kuwait. J Clin Periodontol 2005; 32:809-14.

33. Maria P. Women's health. In: Darby M, Walsh M, eds. Dental Hygiene Theory and Practice, 2nd edn. W.B. Saunders Co. Philadelphia. 2003: 935-8.

34. Thomas NJ, Middleton PF, Crowther CA. Oral and dental health care practices in pregnant women in Australia: a postnatal survey. BMC Pregnancy and Childbirth. 2008; 8:13

35. Hullah E, Turok Y, Nauta M, Yoong W. Self-reported oral hygiene habits, dental attendance and attitudes to dentistry during pregnancy in a sample of immigrant women in North London. Arch Gynecol Obstet 2008; 277:405-9.

36. Blicher B, Joshipura K, Eke P. Validation of self-reported periodontal disease: a systematic review. J Dent Res 2005; 84:881-90.

37. Taylor GW, Borgnakke WS. Self-reported periodontal disease: validation in an epidemiological survey. J Periodontol 2007; 78:1407- 20.

38. Airila-M_ansson S, Bjurshammar N, Yakob M, S€oder B. Selfreported oral problems, compared with clinical assessment in an epidemiological study. Int J Dent Hyg 2007; 5:82-6.

39. Eke PI, Dye BA, Wei L, Slade GD, Thornton-Evans $\mathrm{GO}$ et al. Self-reported measures for surveillance of periodontitis. J Dent Res 2013; 92:1041-47.

40. Giglio JA, Lanni SM, Laskin DM, Giglio NW. Oral health care for the pregnant patient. J Can Dent Assoc 2009; 75:43-8. 